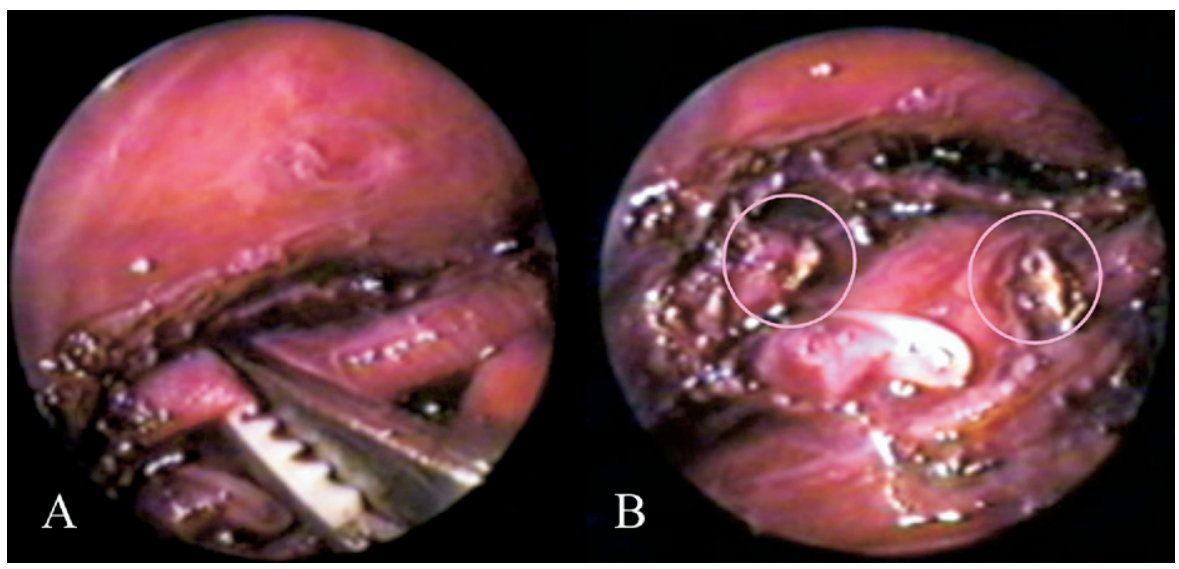

Figure 2. A, The 5-mm Harmonic scalpel is used to divide the posterior aortic arch, which has a 2- to $2.5-\mathrm{mm}$ diameter. $B$, The arch is divided, leaving two well-sealed stumps (circles). The posterior wall of the trachea is relieved from the compression, and the area for the esophageal anastomosis is now clear.

pending. On the basis of the currently available literature on the fields of vascular and general thoracic surgery, we think that thoracoscopy is safe if performed by experienced surgeons. Even when we are reporting a single case, we think that the Harmonic scalpel is a tool that can be safely used for the division of vascular rings of appropriate sizes.

\section{References}

1. Hartenberg MA, Salzberg AM, Krummel TM, Bush JJ. Double aortic arch associated with esophageal atresia and tracheoesophageal fistula. J Pediatr Surg. 1989;24:488-90.
2. Georghiou GP, Stamler A, Berman M, Sharoni E, Vidne BA, Sahar G. Advantages of the ultrasonic Harmonic Scalpel for radial artery harvesting. Asian Cardiovasc Thorac Ann. 2005;13:58-60.

3. Luciani N, Anselmi A, Gaudino M, Nasso G, Glieca F, Martinelli $\mathrm{L}$, et al. Harmonic scalpel reduces bleeding and postoperative complications in redo cardiac surgery. Ann Thorac Surg. 2005;80: 934-8.

4. Matsumoto K, Tsuneyoshi I, Iguro Y, Kinjo T, Yotsumoto G, Ueno M, et al. Effects of ultrasonic skeletonization on internal thoracic and gastroepiploic arteries for coronary artery bypass grafting. Eur J Cardiothorac Surg. 2006;30:592-6.

5. Laje P, Martinez-Ferro M, Grisoni E, Dudgeon D. Intra-abdominal pulmonary sequestration. A case series and review of the literature J Pediatr Surg. 2006;41:1309-12.

\title{
Surgical management of giant left atrial diverticulum
}

Jonathan McGuinness, AFRCSI, Ali Kindawi, FRCSI, Shaf Tajri, MRCS, Kevin Walsh, FRCPI, Lars Nolke, FRCSI, and Alfred E. Wood, FRCSI, Dublin, Ireland

\section{Clinical Summary}

After the incidental finding of a hyperdynamic precordium during a respiratory tract infection and subsequent note of cardiomegaly on a chest $\mathrm{x}$-ray film, an asymptomatic 11/2-year-old girl was referred for transthoracic echocardiography. This showed dex-

\footnotetext{
From the Department of Paediatric Cardiac Surgery and Cardiology, Our Lady's Hospital for Sick Children, Dublin, Ireland.

Received for publication May 2, 2006; accepted for publication Sept 6, 2006.

Address for reprints: Alfred E. Wood, FRCSI, Department of Paediatric Cardiac Surgery, Our Lady's Hospital for Sick Children, Crumlin, Dublin, Ireland (E-mail: jmcguinness2@ rcsi.ie).

J Thorac Cardiovasc Surg 2007;133:820-2

$0022-5223 / \$ 32.00$

Copyright $\odot 2007$ by The American Association for Thoracic Surgery doi:10.1016/j.jtcvs.2006.09.084
}

troposition of the heart secondary to a giant diverticulum of the left atrium (Figure 1,A). Owing to this compression and its risk of progression, combined with the risk of thromboembolism, surgical plication was considered.

Through a left posterolateral thoracotomy, the diverticulum was noted to extend over the left ventricle with the circumflex artery overlying it; therefore, only a selective atrioplasty was undertaken. Postoperatively, the diverticulum was still sizable, and magnetic resonance imaging demonstrated low-grade contraction within the wall of the diverticulum, communicating with the left atrium but not the left ventricle.

Eight months later, with the use of cardiopulmonary bypass, the diverticulum was excluded from the circulation through pericardial patch closure of its orifice from the left atrium. Ten hours postoperatively, circulatory arrest occurred, and the child was placed on extracorporeal membrane oxygenation (ECMO) support. An echocardiogram revealed poor biventricular function with clot filling the diverticulum. Cardiac catheterization revealed globally 


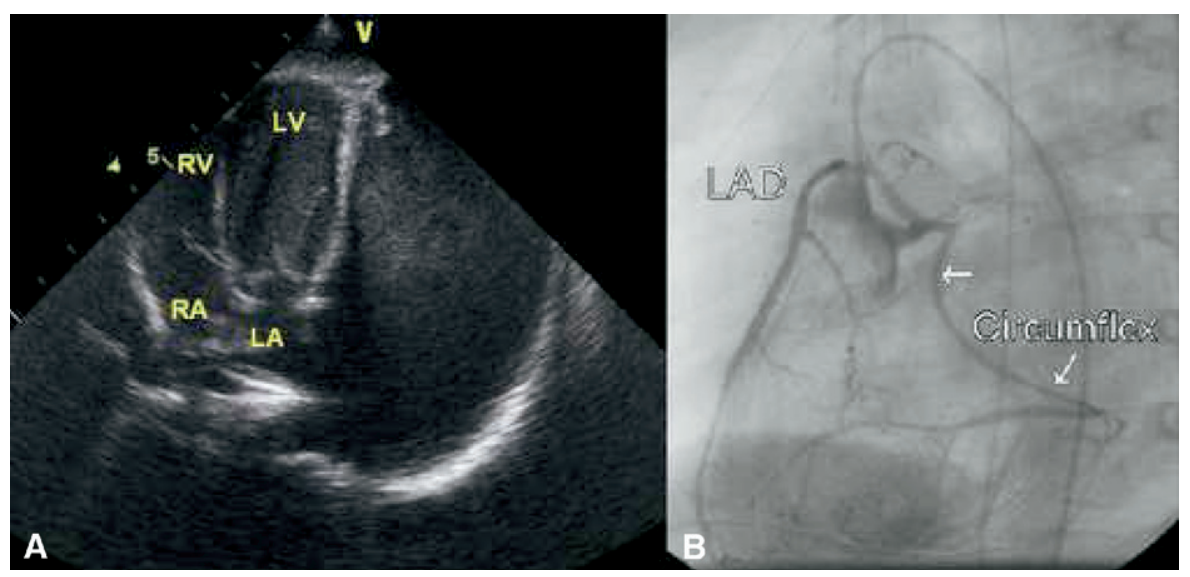

Figure 1. A, Apical 4-chamber view demonstrates the diverticulum extending to the left ventricular apex. $L A$, Left atrium; $L V$, left ventricle; $R A$, right atrium; $\boldsymbol{R V}$, right ventricle. $B$, Left coronary angiogram (left anterior oblique view) showing bowing of the circumflex coronary artery as it passed over the thrombosed diverticulum (arrows) with a dynamic distal stenosis during systole. $L A D$, Left anterior descending coronary artery; Circumflex, circumflex coronary artery.

depressed left ventricular function with a left dominant coronary artery containing a critical dynamic stenosis of the circumflex artery (Figure 1, $B$ ). On the basis of these findings, further surgical repair was undertaken involving an incision over the ventricular component of the diverticulum down to the apex of the left ventricle, with leaflet-like trabeculations resembling a rudimentary atrioventricular valvular apparatus within the diverticulum. The cavity was obliterated internally with pledget-supported sutures between the lateral wall of the true left ventricle and the internal surface of the diverticulum. The diverticulum was then closed with pledget-supported sutures from the atrioventricular groove to the apex of the left ventricle and further plication of the atrial component externally.

Biopsy specimens of the wall of the diverticulum showed endocardium and epicardium with intervening attenuated myocardium. Two days postoperatively, the girl was weaned from ECMO. The echocardiogram at discharge showed no flow within the small residual cavity of the excluded diverticulum (Figure 2) and good left ventricular function, and she had no neurologic deficit.

\section{Discussion}

Atrial and ventricular diverticula are extremely uncommon. The diverticula most commonly present as asymptomatic cardiomegaly on chest $\mathrm{x}$-ray films but can manifest with tachyarrythmias, thromboembolism, or through compression of surrounding structures. ${ }^{1}$ Atrial diverticula can be single or multiple. ${ }^{1}$ Ventricular diverticula are usually single: either a fingerlike outpouching localized near the apex of the ventricle and associated with midline thoracoabdominal defects or a nonapical large pouch with wide connection to the ventricle. ${ }^{2}$ Congenital aneurysms are distinguished from diverticulae by the fact that they are akinetic/dyskinetic pouches. ${ }^{2}$ There have been isolated reports of very large atrial diverticula that extend to the apex of the heart over the ventricular surface. ${ }^{1,3}$ However, the case we report here showed contraction within the myocardium-containing wall of the diverticulum, the circumflex coronary artery extending over the outer surface of the diverticulum, and leaflet-like trabeculations similar to a rudimentary valvular apparatus within the ventricular component of the diverticulum.

Although our patient was asymptomatic apart from a hyperdynamic precordium on examination, surgical resection was consid- ered appropriate because of the large size of the diverticulum compressing the left ventricle on echocardiography, the risk of thromboembolism, and the fact that it represented a potential atrioventricular connection that may facilitate re-entry tachyarrythmias. A review of reported cases of single right atrial diverticula alluded to the $6 \%$ incidence of sudden cardiac death in these patients. ${ }^{1}$ This case emphasized the importance of complete obliteration of the diverticular cavity if excluding it from the left atrium, inasmuch as accumulation of blood with thrombosis in the diverticulum presumably compressed and distorted the abnormal course of the circumflex coronary artery and increased wall tension within the true left ventricular lateral wall, producing ischemia. Also, thorough preoperative assessment with coronary angiography and morphologic magnetic resonance imaging studies are valuable. Other management options that have been reported for such large diverticulae are anticoagulation with observation ${ }^{1,4}$ and heart transplantation. ${ }^{5}$

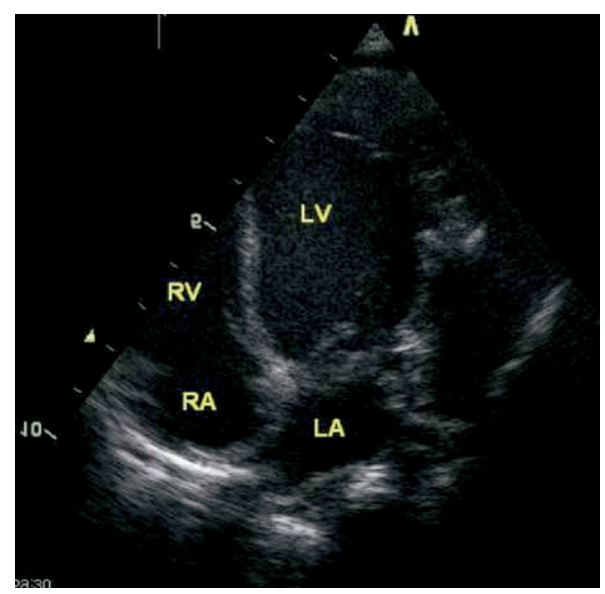

Figure 2. Apical 4-chamber view at discharge showing a markedly reduced diverticular cavity excluded from the left atrium by a pericardial patch. There was no flow within the diverticulum. $L A$, Left atrium; $L V$, left ventricle; $R A$, right atrium; $R V$, right ventricle. 


\section{References}

1. Binder TM, Rosenhek R, Frank H, Gwechenberger M, Maurer G, Baumgartner $\mathrm{H}$. Congenital malformations of the right atrium and the coronary sinus: an analysis based on 103 cases reported in the literature and two additional cases. Chest. 2000;117:1740-8.

2. Marijon E, Ou P, Fermont L, Concordet S, Le Bidois J, Sidi D, et al. Diagnosis and outcome in congenital ventricular diverticulum and aneurysm. J Thorac Cardiovasc Surg. 2006;131:433-7.
3. Stanczyk J, Moll J, Wilczynski J. Prenatal diagnosis of a fetal left atrial diverticulum. Prenat Diagn. 1999;19:1055-7.

4. Parthenakis FI, Kochiadakis GE, Patrianakos AP, Hamilos MI, Mitrouska I, Katsamouris AN, et al. Peripheral arterial embolism due to a left ventricular diverticulum in a young adult. Chest. 2005;127: $1452-4$.

5. Mayer JE Jr, Perry S, O’Brien P, Perez-Atayde A, Jonas RA, Castaneda $\mathrm{AR}$, et al. Orthotopic heart transplantation for complex congenital heart disease. J Thorac Cardiovasc Surg. 1990;99:484-91; discussion 491-2.

\section{Excision of an aneurysm of the left atrial appendage}

Parsia A. Vagefi, MD, Modassir Choudhry, MD, and Alan D. Hilgenberg, MD, Boston, Massachusetts

Supplemental material is available online.

ongenital aneurysmal dilatation of the left atrial appendage is a rare lesion that can commonly be associated with supraventricular arrhythmias, life-threatening systemic embolization, and severe congestive heart failure. ${ }^{1} \mathrm{We}$ report here the case of a 37-year-old man who underwent resection of a giant aneurysm of the left atrial appendage through a limited left thoracotomy without the need for cardiopulmonary bypass (CBP).

\section{Clinical Summary}

A 37-year-old man was told as an adolescent that he had an enlarged heart. He recently sought medical evaluation after reading in the popular press about the death of two young athletes. At the time of presentation he was asymptomatic, and results of his physical examination were unremarkable. An electrocardiogram demonstrated sinus rhythm with frequent premature atrial contractions and left atrial enlargement (Figure E1, a). An echocardiogram showed an echolucent structure measuring $3.6 \times 5.4 \mathrm{~cm}$ adjacent to the base of the left ventricle, with mild extrinsic compression of the ventricle. A chest $\mathrm{x}$-ray film demonstrated a convexity to the left heart border (Figure 1, a). Magnetic resonance imaging showed a left atrial appendage mea-

\footnotetext{
From the Division of Cardiac Surgery, Massachusetts General Hospital, Harvard Medical School, Boston, Mass.

Received for publication Nov 10, 2006; accepted for publication Nov 16, 2006.

Address for reprints: Parsia A. Vagefi, MD, Massachusetts General Hospital, 55 Fruit St, GRB-425, Boston, MA 02114-2696 (E-mail: pvagefi@ partners.org).

J Thorac Cardiovasc Surg 2007;133:822-3

$0022-5223 / \$ 32.00$

Copyright $\odot 2007$ by The American Association for Thoracic Surgery doi:10.1016/j.jtcvs.2006.11.025
}
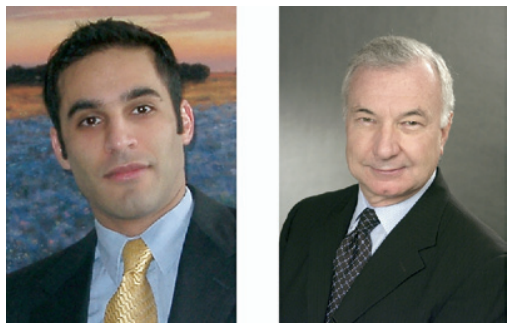

suring $7.2 \times 9.3 \times$

Dr Vagefi and Dr Hilgenberg

$6 \mathrm{~cm}$. A computed to-

mographic angiogram

revealed no evidence of coronary artery disease and confirmed the presence of the aneurysm without evidence of intraluminal thrombus (Figure 1,b). The patient was started on atenolol and warfarin sodium (Coumadin) and was referred for surgery.

The surgical approach was a muscle-sparing, limited left lateral thoracotomy through the fifth intercostal space. A limited longitudinal pericardiotomy revealed an $11-\mathrm{cm}$, thin-walled aneurysm of the left atrial appendage (Figure 2,a). The aneurysm neck had a normal-sized opening into the left atrium. Intraoperative transesophageal echocardiography confirmed the absence of clot within the aneurysm. An atrial clamp was placed across the base of the aneurysm at the junction of the left atrial appendage to the left atrium. Clamping resulted in immediate resolution of the atrial arrhythmia. The aneurysm was excised and the atrial appendage base was closed in two layers with continuous polypropylene suture (Figure 2, $b$ ). The patient was extubated in the operating room, had an uneventful hospital course, and was discharged home on the third postoperative day. At the time of discharge the electrocardiogram demonstrated normal sinus rhythm (Figure E1, b) Pathologic examination demonstrated an atrial wall with marked thinning and fibrosis, consistent with an aneurysm of the atrial appendage.

\section{Discussion}

Multiple surgical approaches have been used for management of aneurysms of the left atrial appendage, including median sternotomy with or without $\mathrm{CPB},{ }^{1-3}$ left thoracotomy, ${ }^{1}$ and minimally invasive endoscopic resection. ${ }^{4}$ It has been suggested that aneurysmectomy aided by CPB is a safer surgical method for this anomaly. ${ }^{2}$ However, in the absence of a broad-based aneurysm neck or thrombus within the aneurysm sac, both of which conditions would require extracorporeal circulation, a lateral thoracotomy without CPB can be used for resection. The latter is a less invasive open approach with improved exposure, because it allows for entry into the chest directly overlying 